\title{
Motherhood wage penalty may affect pronatalist policies
}

\section{If ignored, the motherhood wage penalty may threaten the effectiveness of policies targeting fertility}

Keywords: motherhood wage penalty, cost of children, pronatalist policies, childcare, grandparenting, fertility

\section{ELEVATOR PITCH}

The motherhood wage penalty denotes the difference in wages between mothers and women without children that is not explained by differences in human capital characteristics and labor market experience. As part of the gender pay gap, the motherhood wage penalty can represent a significant cost to being female and having children. If ignored, it may undermine policy initiatives aiming to increase fertility rates in post-socialist countries, such as the costly "baby bonus," which is a government payment to new parents to assist with the costs of childrearing.

\section{KEY FINDINGS}

Pros
$\oplus$ Post-socialist countries continue to experience low
total fertility despite costly pronatalist policies.
$\oplus$ The motherhood wage penalty likely reduces
fertility.
$\oplus$ The motherhood wage penalty can explain the
ineffectiveness of baby bonuses.
$\oplus$ Policy measures to decrease the motherhood
wage penalty may be better alternatives than baby
bonuses, which will also reduce the gender pay gap.
$\oplus$ Ongoing institutional changes in post-socialist
countries are likely to increase the motherhood
wage penalty in the future.

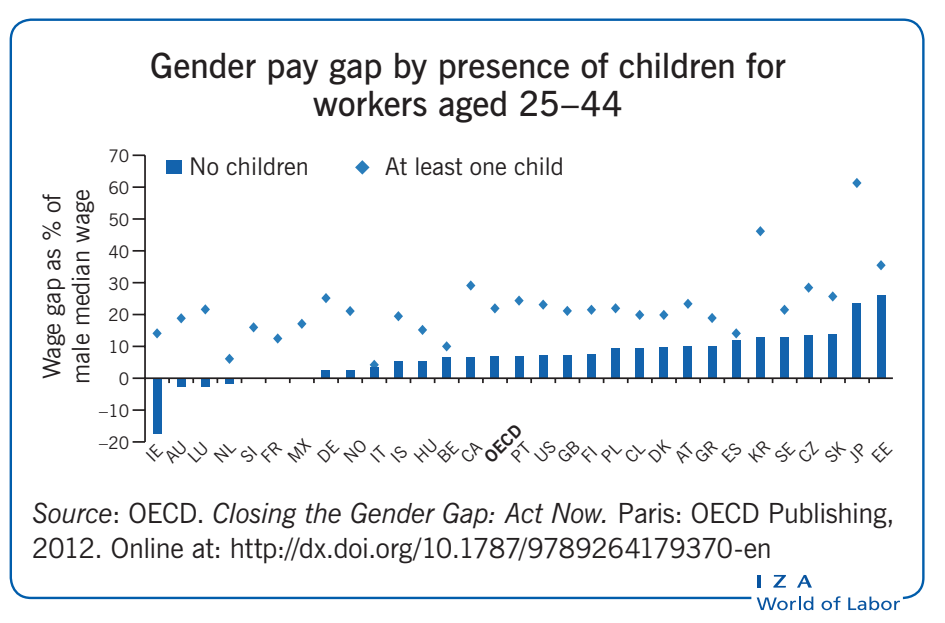

World of Labor

\section{AUTHOR'S MAIN MESSAGE}

The motherhood wage penalty represents a significant share of the gender pay gap and cannot be ignored when considering policies targeted at women. The current strategy in many post-socialist countries of offering so-called "baby bonuses" to increase fertility is not working. Alternative policies aimed at reducing the motherhood wage penalty may prove more effective: for example, publicly provided childcare and moderate length parental leave combined with a campaign to promote cultural support for maternal employment. 


\section{MOTIVATION}

Negative population growth and population aging are some of the most pronounced manifestations of the demographic changes that began in post-socialist countries in the early 1990s. These changes jeopardize these countries' economic growth and raise concerns about the sustainability of their pension systems. Although a number of factors are at play, low fertility seems to be the only one that has attracted the attention of policymakers. The "baby bonus" (BB), a government payment to parents of a new born baby or an adopted child, has been utilized as a policy response to this demographic challenge, despite its cost and little evidence of its effectiveness. This indicates that women and their families face other factors aside from direct costs of childrearing when making decisions about having children.

The motherhood wage penalty (MWP), which serves as a summary measure of a mother's position in the labor market relative to non-mothers (i.e. women without dependent children), is a clear candidate. Targeting a decrease in the MWP via provision of quality public childcare and reducing prejudice against working mothers may represent a more effective tool than the current BB method; furthermore, doing so would have the additional benefit of decreasing the overall gender pay gap. However, the development of such alternative measures requires a comprehensive approach to account for a host of potentially conflicting influences related to current institutions and cultural norms as well as ongoing societal developments in post-socialist countries (e.g. strengthening the rule of law and increasing the retirement age).

\section{DISCUSSION OF PROS AND CONS}

\section{Declining fertility rate and baby bonuses}

Since the start of the transition period, all former socialist states have been going through significant demographic changes, resulting in negative population growth, skewing their overall demographics toward old age. These demographic changes are due to several reasons, including, but not limited to, net emigration, health crises (which have been especially deep and long-lasting in post-Soviet countries) and declining fertility rates (Figure 1). Such demographic trends have been raising concerns among policymakers, particularly with respect to possible consequences for countries' economic development, as well as the sustainability of their pension systems [1]. Migration patterns are mostly driven by individual economic and well-being considerations and difficult and expensive to deal with directly, especially in the absence of state control over the movement of people. Addressing population health crises requires a comprehensive approach, careful planning, and considerable resources, with political dividends unlikely to materialize during the office term of any single ruling government. Thus, a number of post-socialist countries have chosen to address the issue of low fertility by devising pronatalist policies, which, in spite of being costly, are very popular among the electorate and bring immediate political dividends. These policies aim to offset the cost of raising children, thereby encouraging childbearing.

Many post-socialist countries have instituted BBs. They are usually not means-tested, but can be conditioned on other factors, such as parental citizenship and/or purpose (e.g. used toward the child's future education, housing, or health care). Information on the cost of these policies is difficult to collect, primarily because the responsible government 
Figure 1. Total fertility rates in post-socialist countries

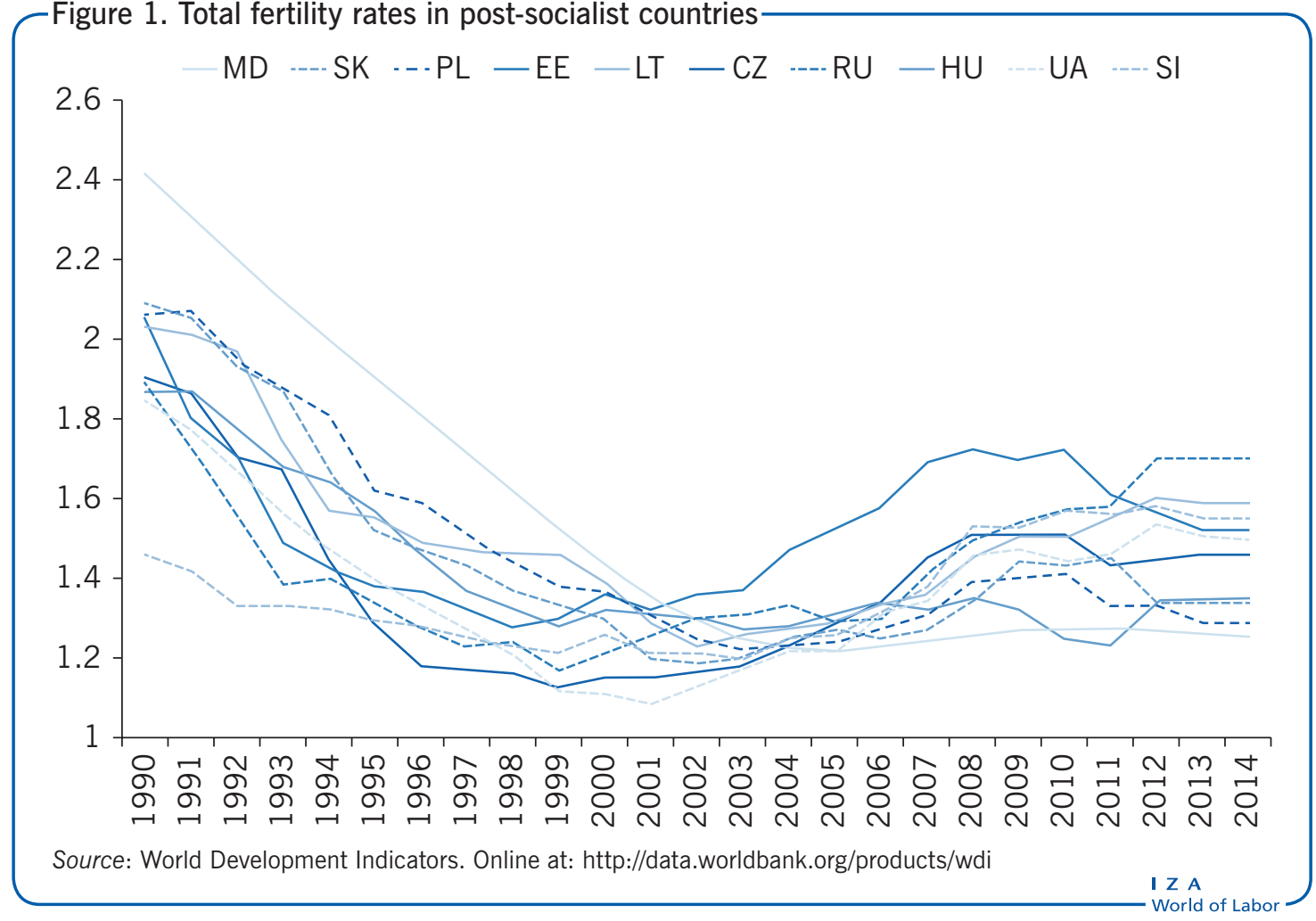

agencies are not willing or able to provide it. For OECD countries, the Family Database documents direct cash transfers to children (including the BB), with the amount ranging from $0.8 \%$ of GDP in Poland to 2.2\% in Hungary in 2011 (Figure 2). In Ukraine, the amount spent on the BB program constituted around $40 \%$ of their social assistance budget in 2010. Russia budgeted RUB 344.5 billion for its national BB program to stimulate fertility in 2015, which constituted around 2\% of GDP. Columns 2 and 3 in Figure 2 provide an illustration of BB sizes in the post-socialist countries for which information is available. As seen, it varies considerably, with the highest compensation levels observed in Hungary, Russia, and Ukraine.

There are no rigorous systematic studies on the effectiveness of such policies in this region. An analysis of the general trends in fertility following the introduction of the BB (Figure 3) may be misleading, as these trends may include effects of other demographic factors and policies. For example, very large BB levels in Ukraine and Russia instituted over the period 2008-2012 have indeed been followed by a slight increase in the total fertility rate. However, this period also coincided with the generation of Soviet baby boomers born in the 1980s finishing education and starting families. Therefore, the observed increase in total fertility may simply reflect this generation's decision to have children to take advantage of generous policies. Such shifts in the timing of births will not lead to higher rates of completed fertility in the future, because they are not having more children, but rather having their children earlier. Moreover, the increases in total fertility are so small that they are unlikely to justify the high overall cost of the BB program.

There are only two studies in the literature that rely on a quasi-experimental setup for assessing the causal effects of similar BB policies. The data come from Canada and Israel [2], [3]. The Canadian case shows an increase of $16.9 \%$ in fertility in response to 
Figure 2. Amount and conditions of baby bonus payments for selected countries

\begin{tabular}{|c|c|c|c|}
\hline Country & $\begin{array}{l}\% \text { of } \\
\text { GDP in } \\
2011\end{array}$ & Baby bonus amount & Conditions \\
\hline Czech Republic & 1 & CZK 13,000 (US\$545) lump-sum. & $\begin{array}{l}\text { First-born child of low-income } \\
\text { mothers only. }\end{array}$ \\
\hline Estonia & 1.9 & $\begin{array}{l}\text { Variable (up to US } \$ 1,560 \text { per month } \\
\text { for a year). }\end{array}$ & $\begin{array}{l}\text { Valid for } 435 \text { days, calculated } \\
\text { based on the average monthly } \\
\text { earnings of the previous fiscal } \\
\text { year. }\end{array}$ \\
\hline Hungary & 2.2 & $\begin{array}{l}\text { Allowances for families: HUF } 12,000 \\
\text { (US } \$ 42 \text { ) per month, per child; from } \\
2015 \text { a non-repayable aid package } \\
\text { of HUF } 10 \text { million (US } \$ 36,000 \text { ) for } \\
\text { the third child plus a loan of the same } \\
\text { amount. }\end{array}$ & $\begin{array}{l}\text { Allowance is not means-tested; } \\
\text { the aid package should be } \\
\text { allocated to an apartment } \\
\text { purchase or house construction. }\end{array}$ \\
\hline Lithuania & $\mathrm{n} / \mathrm{a}$ & 1,400 Litas (US $\$ 460$ lump-sum). & $\begin{array}{l}\text { Every child has the right to the } \\
\text { benefit. }\end{array}$ \\
\hline Poland & 0.8 & $\begin{array}{l}\text { PLN 1,000 (US\$260) lump-sum; } \\
\text { from 2016, PLN } 500 \text { per month } \\
\text { (US } \$ 125) \text {. }\end{array}$ & $\begin{array}{l}\text { Means-tested at PLN } 800 \\
\text { parents' combined monthly } \\
\text { income. }\end{array}$ \\
\hline Russia & 2.1 & $\begin{array}{l}\text { RUB 250,000 (US\$9,400) } \\
\text { lump-sum. }\end{array}$ & $\begin{array}{l}\text { For every child after first-born. } \\
\text { Can only be spent on housing, } \\
\text { education, health care, or } \\
\text { mother's pension. }\end{array}$ \\
\hline Slovakia & 1.6 & $\begin{array}{l}\text { Lump-sum payment to cover } \\
\text { necessities following a child's birth. }\end{array}$ & $\begin{array}{l}\text { Additional annual payment to } \\
\text { parents of triplets. }\end{array}$ \\
\hline Slovenia & 1.7 & $€ 280.75$ lump-sum payment. & $\mathrm{n} / \mathrm{a}$ \\
\hline Sweden & 1.5 & $\begin{array}{l}\text { SEK } 1,050 \text { (US } \$ 117 \text { ) per month for } \\
\text { each child under the age of } 16 \text {. }\end{array}$ & $\mathrm{n} / \mathrm{a}$ \\
\hline UK & 2.6 & $\begin{array}{l}£ 1,076 \text { (US } \$ 1,354) \text { per year for the } \\
\text { first child ( } £ 712 \text { (US\$896) per year for } \\
\text { each subsequent child) for } 16 \text { years ( } 20 \\
\text { if in full-time education) plus one-off } \\
\text { payment of } £ 500 \text { (US } \$ 629 \text { ) for a first- } \\
\text { born (or for multiple birth) if one of the } \\
\text { parents is on certain welfare benefits. }\end{array}$ & $\begin{array}{l}\text { Only applicable if neither of } \\
\text { the parents earn more than } \\
£ 50,000 \text { (US } \$ 61,950 \text { ) per year. }\end{array}$ \\
\hline Ukraine & $\mathrm{n} / \mathrm{a}$ & $\begin{array}{l}\text { UAH } 41,280 \text { (US } \$ 1,720 \text { : provided as } \\
\text { a US } \$ 430 \text { lump-sum, with the rest } \\
\text { distributed equally over three years). }\end{array}$ & $\begin{array}{l}\text { For any child (starting } 2015 \\
\text { based on means test). }\end{array}$ \\
\hline
\end{tabular}

a US\$1,000 increase in the BB [2]. The Israeli study finds a consistently positive effect from the child subsidy on having a third child among families with two children, with the strongest effect documented for poor families (the study was not able to evaluate possible effects on first and second births due to the BB structure) [3]. Comparing these 
Figure 3. Total fertility rates in selected post-socialist countries with baby bonuses

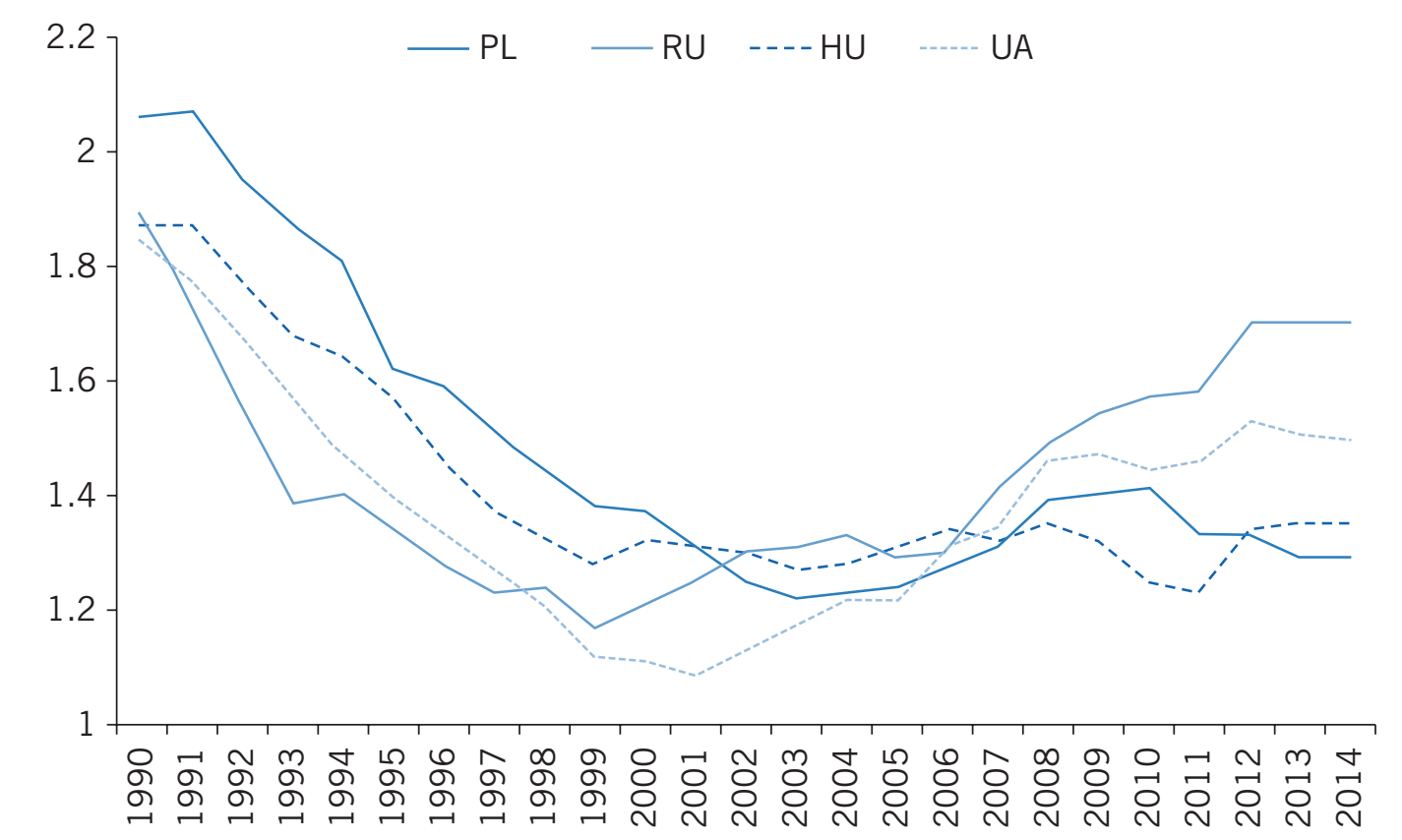

Note: Baby bonus was introduced in Russia in 2007; Ukraine in 2008; and Hungary and Poland in 2016.

Source: World Development Indicators. Online at: http://data.worldbank.org/products/wdi

findings to those that suggest a small effect of income on fertility, the authors of the latter study suggest that only the policies affecting the price of an additional child are likely to be effective, while those that affect income in general are unlikely to have an impact on fertility. Interestingly, throughout the considered period both Canada and Israel had been experiencing a positive trend in fertility, which continued even after a significant reduction in the amount of child subsidies in both countries in 2003.

While these studies provide compelling causal evidence for the BB effect on fertility in two countries, the lack of evidence on substantial increases in fertility rates following the introduction of BB policies in other countries indicates that there is an unaccounted factor that works toward reducing fertility while not being (fully) compensated for by the BB. One obvious candidate is the gap in hourly wages between mothers and nonmothers, i.e. the MWP, which depends on the number of children and may be different for each additional child.

\section{Why the motherhood wage penalty can reduce fertility}

Since the MWP is the remaining difference between wages of mothers and non-mothers after accounting for differences in human capital and working experience, there are three reasons that can explain its existence: mothers' preferences for jobs with special amenities (e.g. working part-time or flexible hours), their lower job productivity relative to non-mothers, and discrimination resulting from stereotyping mothers (i.e. statistical discrimination).

With respect to the first two factors, the evidence on a significant role of preferences is limited [4], [5], and only a few studies focusing on the productivity explanation 
produce the opposite findings. One study does find that the differences among wages of professional sportswomen with and without children are driven by reductions in productivity [6]. On the contrary, the other studies find no significant difference between mothers and non-mothers in academia in terms of the number of publications as a measure of productivity [7], [8]. Overall, the truth may lie somewhere in between-with some decreases in productivity occurring depending on the combination of physical and intellectual components in any given job.

By contrast, the discrimination argument, which refers to the connections between the MWP and employer discrimination in hiring, training, pay, and career tracks, does find much stronger support within the literature. Due to the stereotypical expectations on the burdens imposed by families on mothers' time and energy, employers engage in discriminatory practices against mothers. A number of laboratory experiments and audit studies have shown that female workers identified as mothers were appraised as less competent than non-mothers. Moreover, pregnant female managers were considered less competent and less qualified for promotion than non-pregnant ones. Job applicants identified as mothers were consistently ranked as less competent and less committed, with smaller shares of them being recommended for either hire, promotion, or management training, and in cases when they were recommended for hire, mothers were offered lower starting salaries. At the same time, evaluators posed higher requirements toward them (e.g. permitting fewer late days and demanding higher scores on exams) [9]. Moreover, in-depth interviews with employers in the financial sector in Hungary identified "specific strategies that employers use to shed, demote, and marginalize mothers who are professional workers," which is consistent with the discrimination narrative [10].

There is significant variation in estimates of the MWP across countries. One can distinguish four groups [11], [12]: (i) countries where mothers' wages are practically the same as that of non-mothers (Australia, Belgium, Finland, Greece, Israel, Italy, and Sweden); (ii) countries with a small documented penalty of 5-9\% (Canada, France, Poland, and Slovakia); (iii) countries with moderate MWP of 10-19\% (the Czech Republic, Hungary, Russia, Spain, Ukraine, the UK, and the US); and (iv) countries with very large penalties of $20 \%$ or greater (Germany, Ireland, and the Netherlands).

As higher MWP effectively translates into lower wages for mothers, it makes sense to go back to economic theory and recall how women's wages affect fertility decisions. Basic economic theories suggest that higher wages have two effects on fertility: an "income effect" due to the expansion of a family's budget, and a "substitution effect" because of an increased opportunity cost of having children. The income effect predicts that, with higher wages, women would choose to have more children, while the substitution effect says that women with higher wages lose relatively more in income for every hour that they divert from work to childbearing and caring responsibilities, and thus would choose to have fewer children. Given the fact that childcare is a time-intensive activity performed mostly by women, it is reasonable to expect that the substitution effect will dominate; thus, higher wages would be associated with lower fertility. Empirical research into this question has been limited; that which exists has arrived at mixed results, which have been reconciled by a recent study from Norway. This study finds that the substitution effect dominates with respect to the effect of wages on the likelihood of first birth, while the income effect dominates when considering the likelihood of second and third births [12]. In other words, higher wages decrease a woman's likelihood of having a first child, but 
increase her likelihood of having a second and third child. Another recent theoretical study shows that the income effect is likely to dominate when housing comprises a sufficiently significant cost of child rearing [13]. For instance, if having more children implies incurring higher costs for additional housing, and if housing is in limited supply and/or very expensive, then other costs of child rearing, such as the opportunity cost of the mother's time, become less important. Therefore, when housing costs are high, increases in wages will have a positive effect on fertility.

Despite the lack of empirical evidence, there are two reasons to believe that (higher) wages will positively impact fertility in post-socialist countries, thereby implying that the MWP has a negative effect on fertility. First, the documented decline in fertility is often linked not to the unwillingness to have children per se, but to decisions about whether to have more than one child. The second reason is the historical and ongoing shortage of good quality affordable housing, which is often mentioned among the top three impediments to having children by respondents in various surveys.

\section{Institutions and cross-country variation in the motherhood wage penalty}

Considerable variation in the documented magnitude of the MWP across countries has inspired research into the role of institutional and cultural factors. It has been found that the MWP is affected by policies that target mothers' labor market attachment, such as moderate-length maternity leaves, publicly funded childcare, lower marginal tax rates on second earners, and paternity leave; these policies are all correlated with smaller MWPs. One study also indicates that an interaction exists between institutional characteristics and cultural norms: maternity leaves and public childcare are more effective at reducing the MWP when combined with cultural norms that support maternal employment. However, these types of policies may turn out to be counterproductive if cultural support for maternal employment is low, potentially resulting in higher MWP [11].

The post-socialist countries are located toward the lower end of the MWP distribution spectrum, ranging from small (in most post-socialist EU member states) to medium (e.g. Russia, the Czech Republic, Slovakia, Ukraine). This is not what would be expected given the existing institutions in post-socialist countries: The MWP levels seem to be too low for countries with long maternity leaves and negative attitudes toward maternal employment and too high for countries with high provision of public childcare. Figure 4 shows that the percentage of those people who think that children suffer when their mother works in post-socialist countries is usually higher than in Germany, which has the highest measured MWP, at 33\%, among all the countries for which estimates are available.

There are two possible explanations for such a phenomenon. The first is the quality of the legal environment. Although most post-socialist countries have modern legislation prohibiting discrimination and promoting family-friendly practices at work, widespread corruption within the courts has made it virtually impossible for workers to defend their rights against employers. So, de facto, these countries have quite lax labor markets, where employers do not bear any responsibility for discriminating against mothers and/ or pregnant women. This is often manifested by employers requiring that women provide them with an undated resignation letter at the start of work, which can then be used by the employer if they become pregnant. This situation essentially nullifies the implicit mechanism by which any cost of maternity mandates (however long they may be) is 


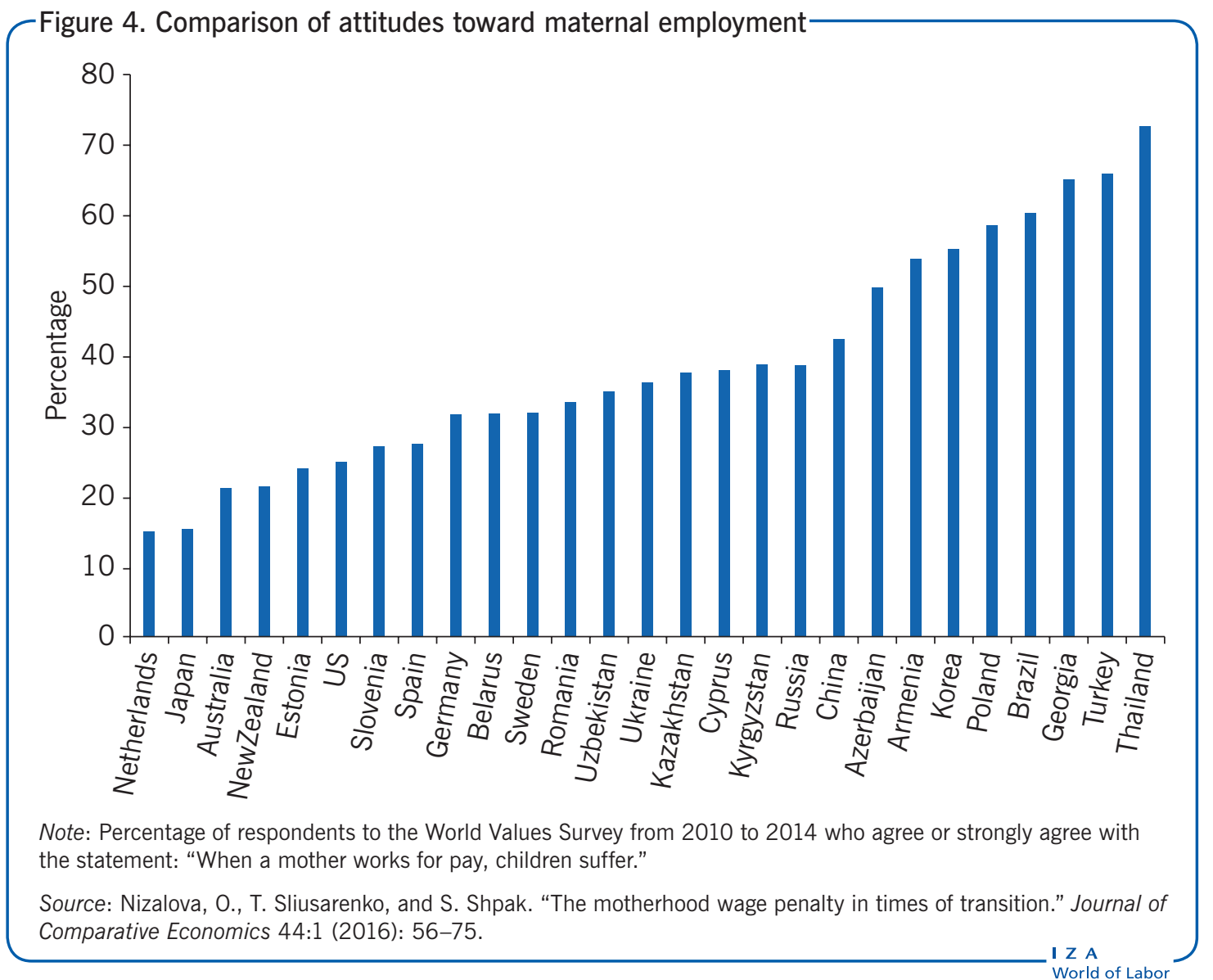

transferred to those entitled to the benefit via lower wages, because employers are in fact not bound by these mandates, as women are unable to protect their rights in courts.

The second explanation is related to cultural norms that favor significant involvement of grandparents in the provision of childcare, age discrimination in labor markets against women older than 45 , and relatively early retirement ages. These conditions imply that alternative high-quality childcare provided by grandparents is more likely to be available to mothers in post-socialist countries than in Western countries, which makes it easier for mothers to focus on work and thus have higher productivity. Based on the available evidence, both explanations should work toward lowering the MWP.

\section{Positive developments may negatively impact the motherhood wage penalty}

Many post-socialist countries are currently undergoing a series of necessary and long overdue reforms. These include strengthening the rule of law and restructuring their pension systems. Despite the obvious need for these developments, there are serious concerns that they may unintentionally lead to increased MWPs. The former would increase the real cost of maternity leave to employers and reduce the scope for age discrimination in the labor market, while the latter would inevitably increase the statutory retirement age. Increasing employers' costs of providing maternity leave could lead to stronger prejudice against women with children. Similarly, curtailing age discrimination 
and increasing the retirement age would decrease the availability of grandparents to provide childcare, thus increasing the opportunity costs of having children.

However, there is no apparent discussion among policymakers about these possible negative impacts on the MWP. In tandem with the much-needed institutional reforms, policy measures should be considered to reduce the MWP.

\section{LIMITATIONS AND GAPS}

The evidence on the MWP and its relationship to fertility is fragmented and should thus be treated with caution. With this in mind, there are several other important limitations that must be mentioned.

First, exploring the direct effect of the MWP on fertility may never be possible. This is because the MWP represents a summary measure of mothers' position in the labor market, estimated at the country level, which means that the data have to satisfy extremely high requirements in order to estimate the MWP magnitude. These requirements make it very costly to obtain results at a reasonable frequency to obtain sufficient longitudinal data needed for rigorous statistical analysis, while cross-country studies will inevitably face the problem of endogeneity.

The second limitation involves the focus on post-socialist countries. There is only a limited number of studies estimating the MWP that adhere to sufficient methodological standards required to identify causal effects. This is primarily due to the absence of panel data with rich information on labor market participation in these countries. Therefore, most of the evidence is drawn from literature focusing on developed countries and is then applied to the post-socialist setting.

Finally, studies considering the role of institutional factors in explaining cross-country variation in the MWP should be updated to make use of a more advanced panel data structure that allows for estimation methods leading to less biased results.

\section{SUMMARY AND POLICY ADVICE}

Given current levels of female labor force participation, any policy measures to increase fertility, such as BB, will not be effective if they ignore the presence of the MWP. Studies exploring the possible causes for the significant variation in the MWP across countries point to a certain combination of institutional and cultural factors that could potentially lead to a lower MWP. However, ongoing and much-needed reforms in post-socialist countries, such as strengthening the rule of law and increasing the retirement age, could end up increasing the MWP. These reforms are inevitable and positive in many respects, yet no discussion currently exists in policy circles about any unintended negative consequences on the MWP, and, by extension, on the overall gender pay gap and fertility. Despite limited empirical evidence on the topic, that which does exist is quite consistent; as such, it should not be ignored in policy debates and should serve as a basis for further exploration into the MWP and fertility issues.

To avoid an increase in the MWP, countries should improve the quality and availability of publicly provided childcare and/or create an attractive business environment for private initiatives in this sector. Additionally, extensive maternity leave (up to three years in 
many countries) should be cut to more moderate levels of approximately one year. These two steps should be carried out in combination with the promotion of cultural norms supporting maternal employment.

\section{Acknowledgments}

The author thanks an anonymous referee and the IZA World of Labor editors for many helpful suggestions on earlier drafts. Previous work of the author contains a larger number of background references for the material presented here and has been used intensively in all major parts of this article. Comments and suggestions from the organizers and participants of the "Gender Equality" panel at the EBRD 2016 Annual Meeting and Business Forum (London, UK) and the "Unlocking Human Potential: Gender in the Region" panel at the SITE 2016 Development Day, "Traces of Transition: Unfinished Business 25 Years Down the Road?" (Stockholm, Sweden) are gratefully acknowledged.

\section{Competing interests}

The IZA World of Labor project is committed to the IZA Guiding Principles of Research Integrity.

The author declares to have observed these principles.

(C) Olena Nizalova 


\section{REFERENCES \\ Further reading}

Budig, M., J. Misra, and I. Boeckmann. "Work-family policy trade-offs for mothers? Unpacking the cross-national variation in motherhood earnings penalties." Work and Occupations 43:2 (2016): 119-177.

Nizalova, O., T. Sliusarenko, and S. Shpak. "The motherhood wage penalty in times of transition." Journal of Comparative Economics 44:1 (2016): 56-75.

\section{Key references}

[1] Lisenkova, K., R. McQuaid, and R. E. Wright. "Demographic change and labour markets." Twenty-First Century Society: Journal of the Academy of Social Sciences 5:3 (2010): 243-259.

[2] Milligan, K. "Subsidizing the stork: New evidence on tax incentives and fertility." The Review of Economics and Statistics 87:3 (2005): 539-555.

[3] Cohen, A., R. Dehejia, and D. Romanov. "Financial incentives and fertility." The Review of Economics and Statistics 95:1 (2013): 1-20.

[4] Budig, M., and P. England. "The wage penalty for motherhood." American Sociological Review 66:2 (2001): 204-225.

[5] Felfe, C. "The motherhood wage gap: What about job amenities?" Labour Economics 19:1 (2012): 59-67.

[6] Kalist, D. "Does motherhood affect productivity, relative performance, and earnings?" Journal of Labor Research 29:3 (2008): 219-235.

[7] Cole, J., and H. Zuckerman. "Marriage, motherhood, and research performance in science." Scientific American 256:2 (1987): 119-125.

[8] Fox, M. F. "Gender, family characteristics, and publication productivity among scientists." Social Studies of Science 35:1 (2005): 131-150.

[9] Benard, S., I. Paik, and S. Correll. "Cognitive bias and the motherhood penalty." Hasting Law Journal 59 (2008): 1359-1388.

[10] Glass, C., and E. Fodor. "Public maternalism goes to market recruitment, hiring, and promotion in postsocialist Hungary." Gender e Society 25:1 (2011): 5-26.

[11] Budig, M., J. Misra, and I. Boeckmann. "The motherhood penalty in cross-national perspective: The importance of work-family policies and cultural attitudes." Oxford Journal 19:2 (2012): 163-193.

[12] Kornstad, T., and M. Ronsen. Women's Wages and Fertility Revisited. Statics Norway Research Department Discussion Paper No. 7, 2014.

[13] Day, C., and R. Guest. "Fertility and female wages: A new link via house prices." Economic Modelling 53 (2016): 121-132.

\section{Online extras}

The full reference list for this article is available from:

http://wol.iza.org/articles/motherhood-wage-penalty-may-affect-pronatalist-policies

View the evidence map for this article:

http://wol.iza.org/articles/motherhood-wage-penalty-may-affect-pronatalist-policies/map 